\title{
DEA with non-monotonic variables. Application to EU governments' macroeconomic efficiency
}

G. Villa; S. Lozano

\author{
Artículo publicado en: \\ Journal of the Operational Research Society (2016), 67, 1510-1523 \\ doi: 10.1057/jors.2016.36
}

\begin{abstract}
Conventional Data Envelopment Analysis (DEA) considers monotonic variables, i.e. the lower the inputs and the larger the outputs, the better. There are, however, occasions when the monotonicity of a variable with respect to efficiency depends on the value of the variable, i.e. in a certain range of values an increase in the variable is desirable, while in another range it is a decrease of the variable that is desirable. In this paper, a DEA model that solves problems considering non-monotonic variables is proposed. An application to assess the macroeconomic efficiency of European Union (EU) Member States, as regards taxation, gross debt, GDP growth and employment is presented.
\end{abstract}

Keywords: DEA; non-monotonic variables; membership functions; macroeconomic efficiency

\section{Introduction}

Data Envelopment Analysis (DEA) is a well known non-parametric methodology for assessing the efficiency of a number of homogeneous Decision Making Units (DMUs) (Cooper et al., 2000; Zhu, 2002; Färe and Grosskopf 2004). These DMUs are assumed to consume inputs (i.e. resources) and generate outputs (i.e. goods and/or services). Conventional DEA considers monotonic variables, i.e. the lower the inputs and the larger the outputs, the better. Sometimes, however, identifying the input/output status of a variable is not easy because the behavior of some variables may not fit the definition of resource or product. Think about variables such as temperature, pressure, speed or frequency. For certain physical systems, these variables have to be maintained in a specific interval for the system to reach its highest performance. When they are out of that interval, performance worsens. 
Similarly, the value of some blood test results must be within a certain range for a person to be considered healthy and the further away they are from the limits of the normal range, the worse the condition. Another potential application would be the assessment of the efficiency of olive orchards (or any other crop for that matter) in which some variables are monotonous (like the land input or the amount produced output) but others (like accumulated rainfall or manure) can behave in a non-monotonic way. Another example might be the assessment of the efficiency of mobile phones. Again, some variables (like the price input or the memory, battery life or screen resolution outputs) are monotonous but there are also variables (like the screen size) that can behave in a non-monotonic way.

The above remarks lead us to think that there exist situations in which a certain variable cannot be considered as an input or an output but act as an input within a certain range of values (where the efficiency increases when the variable decreases) and as an output within another range (where the efficiency increases if the variable increases). This is related to, but different from, the DEA concept of flexible variables (or dualrole factors), i.e. variables that can be considered either as an output or an input. There is extensive literature on this type of DEA model. Thus, Beasley $(1990,1995)$ was the first to consider a variable (research income) as both an input and output when he studied the efficiency of the research productivity of university departments in the UK. Later on, Cook et al. (2006) and Cook and Zhu (2007) proposed a methodology to model that type of DEA problem. Toloo (2009) proposed a modified model that corrected a computational problem in the approach of Cook and Zhu (2007). Amirteimoori and Emrouznejad (2012) proposed that the models in Toloo (2009) and Cook and Zhu (2007) were equivalent and overestimate the efficiency, however, Toloo (2014) proved that their claims are incorrect. Amirteimoori and Emrouznejad (2011) introduced a new modified enhanced model while Amirteimoori et al. (2013) proposed a flexible slack-based measure (FSBM) of efficiency, modifying the SBM model of Tone (2001) to deal with dual role factors. Toloo (2012) illustrated that in order to deal with the flexible measures, alternative optimal solutions have to be considered; otherwise incorrect results might occur. His model can identify so-called share cases, i.e. when the efficiency scores of a DMU is equal whether the flexible measure is considered either as input or as output. These share cases must not be taken into account for classifying inputs and outputs.

Shabani et al. (2011) proposed a non-linear dual role factor DEA model (solved using a genetic algorithm) while Shabani and Farzipour Saen (2015a) propose a super-efficiency measure in the presence of dual role factors when FDH technology is applied. Chen (2014) brings a new perspective to the problem by means of the introduction of the concept of joint 
technology. When the flexible variable acts as an input, both regular inputs and dual role inputs produce outputs, determining a technology which is different from that when the flexible variable acts as an output and then regular inputs produce regular outputs and the dual role output. Many authors have applied dualrole factor DEA models to different problems, such as supplier selection (Toloo and Barat, 2015), international market selection (Shabani and Farzipour Saen, 2013), prospective benchmarks in green supply chain (Shabani and Farzipour Saen, 2015b), etc.

Summarizing, although several different models have been proposed to handle dual role factors in DEA, so far there are no studies that deal with applications in which some variables can be considered as either an input or an output, depending on their values. Specifically, we consider those cases in which a variable might be considered as an output within a range of values (where increasing the variable is desirable) while the same variable can be considered as an input in another range of values (in which decreasing the variable is desirable). We call those variables non-monotonic to distinguish them from the conventional input and output variables, which are monotonic.

Therefore, in this paper, we first present an innovative DEA approach to handle nonmonotonic variables and then we apply that approach to the problem of assessing the macroeconomic efficiency of EU governments. The structure of the paper is the following. In Section 2 the proposed DEA model is formulated and discussed. The model is applied, in Section 3, to benchmarking the performance of EU Member States during the period 20062013. Finally, section 4 summarizes and concludes.

\section{DEA model with non-monotonic variables}

The first step in conventional DEA is to infer the Production Possibility Set (PPS, also known as the DEA technology). This is done using some basic axioms (such as envelopment, free disposability and convexity) and applying the Principle of Minimum Extrapolation. In this way, the Variable Returns to Scale (VRS) DEA technology results. Thus, let

index on DMUs, from 1 to $n$

i

index for inputs, from 1 to $\mathrm{m}$

$\mathrm{k}$

index for outputs, from 1 to $p$

$\mathrm{X}_{\mathrm{ij}}$

input $\mathrm{i}$ consumed by DMU $\mathrm{j}$ 
The VRS PPS corresponds to:

$$
T(x, y)=\left\{\sum_{j=1}^{n} \lambda_{j} x_{i j} \leq \hat{x}_{i} ; \sum_{j=1}^{n} \lambda_{j} y_{k j} \geq \hat{y}_{k} ; \sum_{j=1}^{n} \lambda_{j}=1 ; \lambda_{j} \geq 0\right\}
$$

In this article, in addition to inputs and outputs, we consider non-monotonic variables. Those variables are not considered to be freely disposable. It would not make much sense to assume that, given a feasible operating point, reducing one of these variables (or increasing it) without limit, as free disposability implies, is always feasible. Nor can it be guaranteed that reducing the variable (or increasing it) corresponds to lower efficiency and moving away from the efficient frontier. Therefore, since assuming free disposability of non-monotonic variables does not seem reasonable it has been not considered for this type of variables.

Let

r $\mathrm{V}_{\mathrm{rj}}$

The resulting non-monotonic VRS PPS is:

$$
T\left(\hat{\mathbf{x}}, \hat{\mathbf{y}}_{j}, \hat{\mathrm{v}}\right)=\left\{\sum_{\mathrm{j}=1}^{\mathrm{n}} \lambda_{\mathrm{j}} \mathrm{x}_{\mathrm{ij}} \leq \mathrm{x}_{\mathrm{i}} ; \sum_{\mathrm{j}=1}^{\mathrm{n}} \lambda_{\mathrm{j}} \mathrm{y}_{\mathrm{kj}} \geq \hat{\mathrm{y}}_{\mathrm{k}} ; \sum_{\mathrm{j}=1}^{\mathrm{n}} \lambda_{\mathrm{j}} \mathrm{v}_{\mathrm{rj}}=\widehat{\mathrm{v}}_{\mathrm{r}} ; \sum_{\mathrm{j}=1}^{\mathrm{n}} \lambda_{\mathrm{j}}=1 ; \lambda_{\mathrm{j}} \geq 0\right\}
$$

Therefore, a first difference with respect to conventional DEA is that the PPS required for non-monotonic variables differs from the usual monotonic inputs and outputs PPS in that values of the non-monotonic variables outside the observed range are not considered feasible. Actually, only those values within the corresponding convex hull are possible.

A second, more striking difference is that, in order to determine the efficient frontier, it is necessary to define the range of values where the non-monotonic variables are monotonically increasing or monotonically decreasing with respect to efficiency. In other words, for each non-monotonic variable, the range of values for which it behaves as an input and an output must be determined. We consider only non-monotonic variables $\mathrm{v}_{\mathrm{r}}$ for which:

- there is an interval $\left(\mathrm{v}_{\mathrm{r}}^{\text {ideal,min }}, \mathrm{v}_{\mathrm{r}}^{\text {ideal,max }}\right)$ in which the variable $\mathrm{v}_{\mathrm{r}}$ is optimal, i.e. it takes its best possible value, and therefore it contributes maximally to efficiency in the sense that the variable cannot be improved by changing this variable 
- there is an interval $\left(\mathrm{v}_{\mathrm{r}}^{\mathrm{min}}, \mathrm{v}_{\mathrm{r}}^{\text {ideal,min }}\right)$ in which the variable acts as an output, so that increasing its value is desirable

- there is an interval $\left(\mathrm{v}_{\mathrm{r}}^{\text {ideal,max }}, \mathrm{v}_{\mathrm{r}}^{\max }\right)$ in which the variable acts as an input, so that decreasing its value is desirable

Note that, as shown in Figure 1, this type of variable can be described through a Trapezoidal Fuzzy Number $(\operatorname{TrFN})\left(\mathrm{v}_{\mathrm{r}}^{\mathrm{min}}, \mathrm{v}_{\mathrm{r}}^{\text {ideal,min }}, \mathrm{v}_{\mathrm{r}}^{\text {ideal,max }}, \mathrm{v}_{\mathrm{r}}{ }^{\mathrm{max}}\right)$ so that the corresponding membership function $\mu_{\mathrm{r}} \mathrm{V}_{\mathrm{r}}$ represents the desirability of the corresponding value of the variable. Note also that we can define a similar $\mathrm{TrFN}$ to represent the desirability of the input and output variables $\left(0,0, \mathrm{x}_{\mathrm{i}}^{\text {ideal,max }}, \mathrm{x}_{\mathrm{i}}^{\max }\right)$ and $\left(\mathrm{y}_{\mathrm{k}}{ }^{\min }, \mathrm{y}_{\mathrm{k}}{ }^{\text {ideal,min }}, \infty, \infty\right)$, respectively. Here, $\mathrm{x}_{\mathrm{i}}^{\text {ideal,max }}$ corresponds to the maximum value of input consumption in the ideal case and it may, in principle, be equated to the minimum value of that input for the observed DMUs. The maximum acceptable value (i.e. higher values are completely undesirable) of that input, $\mathrm{x}_{\mathrm{i}}{ }^{\max }$, on the other hand, can be, in principle, equated to the maximum value of that input for the observed DMUs. Analogously, $\mathrm{y}_{\mathrm{k}}{ }^{\mathrm{min}}$ and $\mathrm{y}_{\mathrm{k}}{ }^{\text {ideal,min }}$ represent the minimum acceptable value and the minimum ideal value, respectively, for output $\mathrm{k}$ and can be equated, in principle, to the minimum and maximum values of that output for the observed DMUs.

Figure 1 (about here)

Given the TrFN corresponding to the desirability membership functions of the different inputs, outputs and non-monotonic variables, the relative efficiency of a DMU can be defined as the maximum possible increase in the desirability of these variables with respect to their observed values. A DMU is thus relatively efficient if the desirability of none of its inputs, outputs and non-monotonic variables can be improved according to the corresponding TrFN. The DEA model to obtain the corresponding efficiency score is formulated below but first, since both the PPS and the efficient frontier, in the case of non-monotonic variables, differ from those of a conventional DEA, it is convenient to illustrate the concepts with a simple numerical example. However, in order to be able to represent the data in a bidimensional plot, we will consider the case of no monotonic inputs, a single monotonic output $\mathrm{y}$ and a single non-monotonic variable $\mathrm{v}$.

Figure 2 plots 11 DMUs together with the reference values of the $\operatorname{TrFN}$ of the nonmonotonic variable (corresponding to the four vertical dashed lines). The corresponding reference values of the output variable are $\mathrm{y}_{\mathrm{k}}{ }^{\mathrm{min}}=5$ and $\mathrm{y}_{\mathrm{k}}{ }^{\text {ideal,min }}=30$, slightly below and 
slightly above, respectively, the minimum and maximum observed output values. The nonmonotonic PPS given by equation (2) corresponds to the area delimited by the polygonal line and the corresponding efficient frontier is just the small segment shown in bold, which includes one of the observed DMUs (having the maximum output) plus part of the segment that links that DMU and the one with the lowest value of the non-monotonic variable. Any other point $(\hat{v}, \widehat{y})$ within the PPS is not efficient as either the desirability of the monotonic output (mo) $\mu^{\text {mo }} \hat{y}$ and/or of the non-monotonic (non_m) variable $\mu^{\text {non_m }} \hat{\mathrm{v}}$ can be increased.

Figure 2 (about here)

In the case shown in Figure 2 one of the observed DMUs belongs to the efficient frontier. Note however, that, unlike what happens in traditional DEA models, when nonmonotonic variables are considered, the efficient frontier can contain operating points (like the point labeled Q in Figure 2) that are a linear combination of observed DMUs some of which do not necessarily belong to the efficient frontier). Figure 3 shows four other scenarios corresponding to different values of the parameters $v_{r}$ ideal,min and $v_{r}^{\text {ideal,max }}$. Thus, in the case shown in panel a), we again have that one of the two DMUs with the maximum output value is efficient and that the efficient frontier contains operating points formed as a linear combination of DMUs not all of which belong to the efficient frontier. In panel b), the efficient frontier contains maximum output points but none of them corresponds to observed DMUs. This never happens in conventional DEA, in which at least one of the observed DMUs is always deemed efficient. The case shown in panel c) is similar to that of panel a) except that the maximum output efficient DMU is different. Finally, in panel d), we have two efficient DMUs, one of which corresponds to the maximum output. As it can be seen in these examples, in non-monotonic DEA the efficient frontier does not necessarily include the observed DMUs. Although that may seem surprising at first glance, it is not so strange. Thus, in Network DEA it can happen that no DMU is deemed efficient since for a DMU to be efficient all its processes must be efficient, something which is not very likely.

Figure 3 (about here)

In order to formulate the proposed non-monotonic DEA model, let 


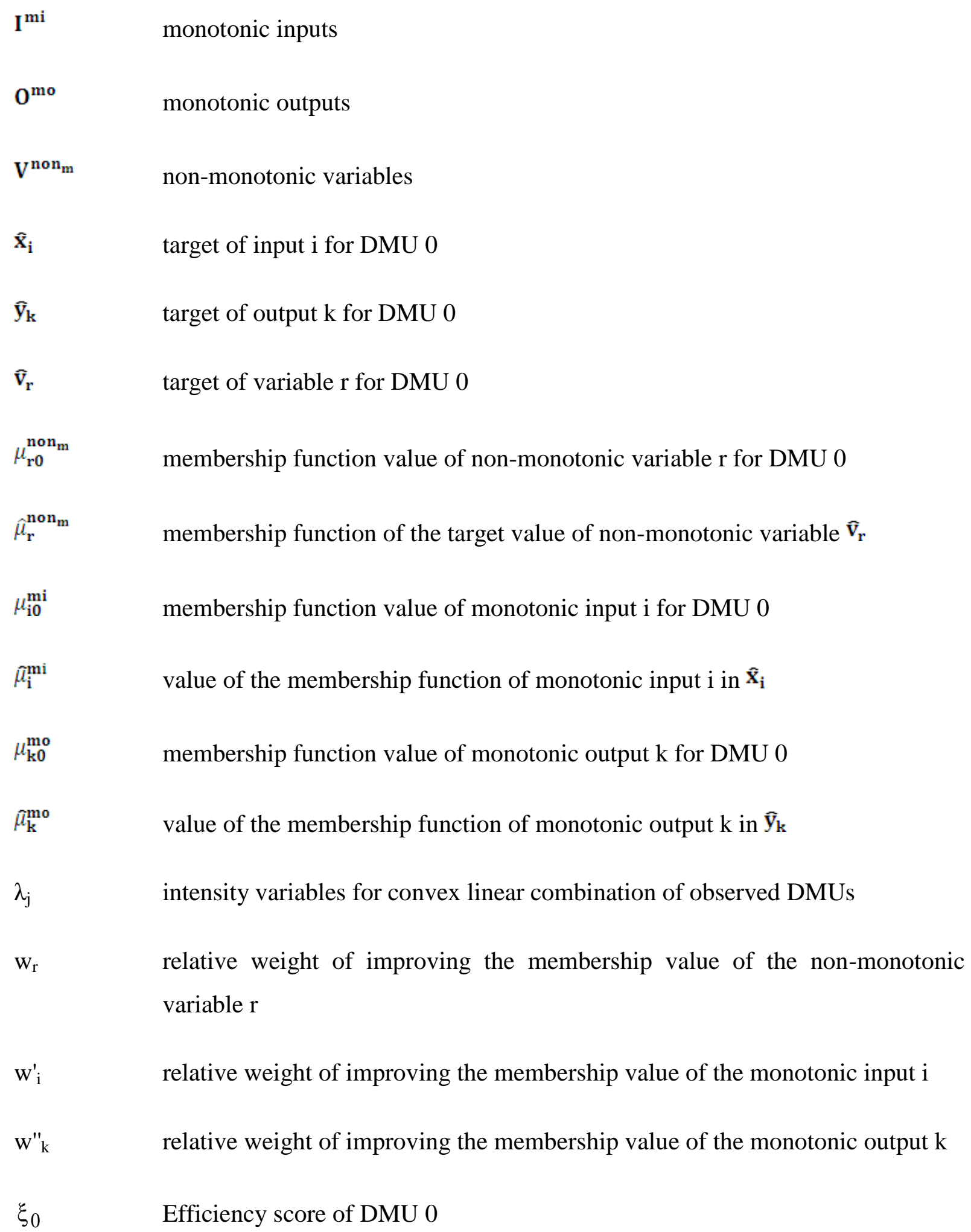

The proposed non-monotonic DEA model can be formulated as:

$\operatorname{Max} \sum_{\mathrm{r}=1}^{\mathrm{h}} \mathrm{w}_{\mathrm{r}}\left(\hat{\mu}_{\mathrm{r}}^{\mathrm{non}}-\mu_{\mathrm{r} 0}^{\mathrm{non}_{\mathrm{m}}}\right)+\sum_{\mathrm{i}=1}^{\mathrm{m}} \mathrm{w}_{\mathrm{i}}^{\prime}\left(\hat{\mu}_{\mathrm{i}}^{\mathrm{mi}}-\mu_{\mathrm{i} 0}^{\mathrm{mi}}\right)+\sum_{\mathrm{k}=1}^{\mathrm{p}} \mathbf{w}_{\mathrm{k}}^{\prime \prime}\left(\hat{\mu}_{\mathrm{k}}^{\mathrm{mo}}-\mu_{\mathrm{k} 0}^{\mathrm{mo}}\right)$

s.t. 


$$
\begin{aligned}
& \sum_{j=1}^{n} \lambda_{j} x_{i j} \leq x_{i 0} \quad \forall i \in I^{m i} \\
& \sum_{j=1}^{n} \lambda_{j} y_{k j} \geq y_{k 0} \quad \forall k \in 0^{m o} \\
& \sum_{j=1}^{n} \lambda_{j} x_{i j}=\hat{x}_{i} \quad \forall i \in I^{m i} \\
& \sum_{j=1}^{n} \lambda_{j} y_{k j}=\widehat{y}_{k} \quad \forall k \in 0^{m o} \\
& \sum_{j=1}^{n} \lambda_{j} v_{r j}=\widehat{v}_{r} \quad \forall r \in v^{\text {non }_{m}}
\end{aligned}
$$

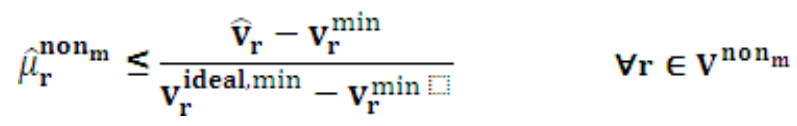

$$
\begin{aligned}
& \hat{\mu}_{\mathrm{r}}^{\mathrm{non}_{\mathrm{m}}} \leq \frac{\mathbf{v}_{\mathrm{r}}^{\max }-\widehat{v}_{\mathrm{r}}}{\mathbf{v}_{\mathbf{r}}^{\max }-\mathbf{v}_{\mathrm{r}}^{\text {ideal,max }}} \quad \forall \mathrm{r} \in \mathbf{V}^{\mathrm{non}_{\mathrm{m}}}
\end{aligned}
$$

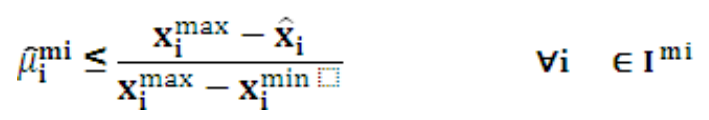

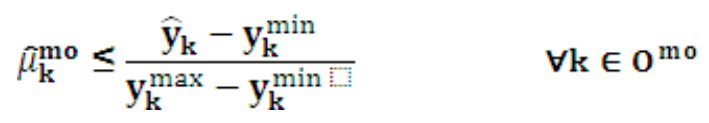

$$
\begin{aligned}
& \sum_{j=1}^{n} \lambda_{j}=1 \\
& \mu_{\mathrm{r} 0}^{\mathrm{non}_{\mathrm{m}}} \leq \widehat{\mu}_{\mathrm{r}}^{\mathrm{non}_{\mathrm{m}}} \leq 1 \quad \forall \mathrm{r} \in \mathrm{V}^{\mathrm{non}_{\mathrm{m}}} \\
& \mu_{\mathrm{i} 0}^{\mathrm{mi}} \leq \widehat{\mu}_{\mathrm{i}}^{\mathrm{mi}} \leq 1 \quad \forall \mathrm{i} \in \mathrm{I}^{\mathrm{mi}} \\
& \mu_{\mathrm{k} 0}^{\mathrm{mo}} \leq \widehat{\mu}_{\mathrm{k}}^{\mathrm{mo}} \leq 1 \quad \forall \mathrm{k} \in 0^{\mathrm{mo}} \\
& \lambda_{\mathrm{j}} \geq \mathbf{0} \quad \forall \mathrm{j}
\end{aligned}
$$

This is a Linear Programming (LP) model with $2 *(h+m+p)+n$ continuous variables and $5 \mathrm{~h}+4 *(\mathrm{~m}+\mathrm{s})$ constraints. The model measures the efficiency of DMU 0 by maximizing the weighted increase in the degree of membership of all the variables with respect to the observed values. Constraints (4) and (5) guarantee that inputs will not be increased and outputs will not be decreased. Constraints (6), (7) and (8) define the target values of the different variables. All these constraints, together with (13) and (17), actually implement the envelopment, free disposability of inputs and outputs and convexity assumptions and together define points $\left(\hat{\mathrm{x}}_{\mathrm{i}}, \widehat{\mathrm{y}}_{\mathrm{k}}, \widehat{\mathrm{v}}_{\mathrm{r}}\right)$ that belong to the non-monotonic PPS. 
The following sets of constraints are related to the membership function values of the different variables. Thus, constraints (9) and (10), together with (14), compute the target membership function value of each non-monotonic variable $\widehat{\mathbf{v}}_{\mathbf{r}}$. Constraints are similar (11) and (12), together with (15) and (16), compute the corresponding target membership function value for each (monotonic) input and output variable.

Note that constraints (14)-(16) guarantee that the target degree of membership of each variable, monotonic or non-monotonic must be greater than or equal to that observed for DMU 0. Finally, objective function (3) can be interpreted as maximizing the weighted increase of those target membership function values. This objective function looks similar to a weighted slacks maximization in a conventional DEA model. It should be noted, however, that in the proposed model all variables (both monotonic and non-monotonic) have been translated into their corresponding membership function values, which are dimensionless variables and can therefore be summed.

If the optimal value of the objective function is zero, then DMU 0 is efficient. Since the values of all the membership functions are between 0 and 1 and, assuming that the weights are normalized,

$$
\sum_{\mathrm{r}=1}^{\mathrm{h}} \mathbf{w}_{\mathrm{r}}+\sum_{\mathrm{i}=1}^{\mathrm{m}} \mathbf{w}_{\mathrm{i}}{ }_{\mathrm{i}}+\sum_{\mathrm{k}=1}^{\mathrm{p}} \mathbf{w}_{\mathrm{k}}^{\prime \prime}=\mathbf{1}
$$

anda normalized efficiency score for DMU 0 can be computed as

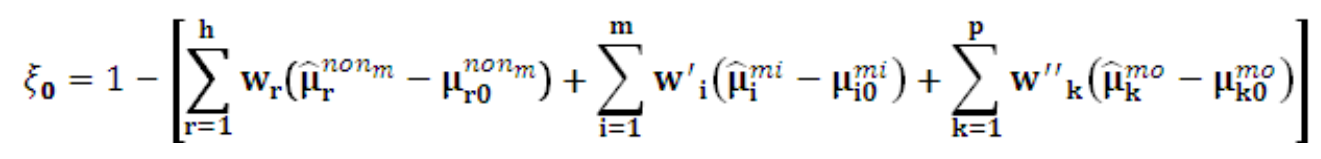

Using the proposed non-monotonic DEA model with the dataset shown in Figure 2 and considering equal weights $(\mathrm{w}=\mathrm{w}$ " $=0.5)$, we can compute the targets and corresponding membership function values of each DMU, as well as its efficiency score. They are shown in Table 1 together with the observed values of the variables, their corresponding membership function values and the benchmarks used to compute the targets. The row corresponding to the only DMU deemed efficient (namely DMU 3) is shown in grey. All the other DMUs are projected onto this efficient DMU except DMUs 2 and 9, which are projected onto point $(\hat{v}=40, \hat{y}=26.05$ ) labeled $Q$ in Figure 2, which is a convex combination of DMU 3 (which is efficient) and DMU 4 (which is not). 
It should be noted that this model formulation is the one to be used when the observed values of all the variables (monotonic or non-monotonic) are within the support of their respective desirability membership functions. If that is not the case, then a modified, slightly more complex formulation with binary variables, is required. The corresponding MixedInteger Linear Programming (MILP) model is presented and explained in the Appendix.

Note also that the membership function used in the proposed approach for the nonmonotonic variables defines specific ranges for these variables so that the effect of a change of the variables on the objective function depends on the range on which the variables lie. Often, as in the example of the blood test results or in the example of the olive orchards, the limits of these ranges can be identified by consensus of experts. On other occasions the corresponding limits may be more subjective and may depend on the Decision Maker (DM) and his value judgment. In fact, the existence of such a DM is implicit in the fact that the proposed approach considers a weighted objective function which weights differently the increases in the membership function values of the different inputs, outputs and nonmonotonic variables.

Finally, although the proposed approach has considered VRS, in principle it is possible to extend it to the CRS case. A scalability assumption may be considered when building the corresponding technology and that will be no problem. The fact that the membership function of the non-monotonic variables establishes fixed ranges for these variables can limit, however, the extent to which the CRS efficient frontier may span.

\section{Application to macroeconomic efficiency of EU governments}

In this section the proposed approach is used to assess the macroeconomic efficiency of EU governments. DEA has been extensively used to study public sector efficiency, i.e. to check whether public sector expenditure (on health, education and infrastructure, for example) pays off in terms of social and economic outcomes (e.g. Afonso et al., 2005; Hauner and Kyobe, 2010; Badun et al., 2014). The closest DEA applications are, however, those that have studied the macroeconomic performance of countries, taking into account variables such as total government expenditure, tax burden, fiscal deficit, debt and Gross Domestic Product (GDP) growth (e.g. De Witte and Moesen, 2010; Wang and Alvi, 2011; Sahoo and Acharya, 2012; Moreno and Lozano, 2014). 
The reason why we need to consider a non-monotonic DEA approach in this application is because there is ample empirical evidence of an inverted U-shaped relationship between government spending and GDP growth, the so-called BARS curve (Facchini and Melki, 2013; Badun et al. 2014). Similarly, there seems to exist a non-linear, inverted U-type relationship between public debt and GDP growth, the so-called Debt Laffer curve (e.g. Claessens, 1990; Megersa and Cassimon, 2015). Note also, in this regard, the statements of some economic authorities, such as the current President of the EU Commission (Junker, $2014)^{1}$.

Figure 4 shows the real GDP growth rate (gdp) and the total employment rate (emp), respectively, as a function of the tax revenue (tax) and gross debt (debt), both as a percentage of GDP, for the period 2006-2013 (Eurostat Database, 2015). In these plots it can be seen that there is no monotonic relationship, neither between tax burden and GDP growth or employment rate nor between gross debt and GDP growth or employment rate. That is why we have considered in this application that tax burden and gross debt are non-monotonic variables, while GDP growth and employment rate are monotonic output variables, as shown in Figure 5.

$=$ Figure 4 (about here)

Figure 5 (about here)

Table 2 shows some summary statistics of the variables considered for the period 2006-2013. This period of time is the longest interval with available data for the majority of the EU 28 countries. Only data about the gross debt of Greece from 2006 to 2010 are not available in the Eurostat Database (2015).

The statistics in Table 2 show the wide range in the value of the tax burden of EU Member States (e.g. in year 2013, 27.2\% of GDP in the case of Lithuania versus $48.6 \%$ of GDP in the case of Denmark). Even wider is the range of observed values for the gross debt (e.g. in year 2013, 10.1\% of GDP in the case of Estonia versus $175 \%$ of GDP in the case of

\footnotetext{
1“‘[...] deficits and high levels of debt do not automatically produce growth. If that were so, if high levels of deficit and debtled to growth, then Europe ought to be growing as never before in its history, for wehave never been as indebted as we are today".
} 
Greece). The GDP growth rate also has ample variability, both among years and within each single year (e.g. in year 2013, $-5.4 \%$ in the case of Cyprus versus $4.4 \%$ in the case of Luxembourg). The employment level has a relatively smaller range of variation (e.g. in year 2013, $72.5 \%$ in the case of Greece versus $94.8 \%$ in the case of Germany). Given the wide spread of the dataset, let us assume the desirability membership functions shown in Figure 6. These desirability membership functions assume as "ideal" the tax burdens within the interval [30\%,40\%] and completely undesirable tax burdens below $25 \%$ and above 50\%. Similarly, the ideal values considered for the gross debt correspond to the interval [10\%,60\%] with complete undesirability for $0 \%$ debt and for debt above 120\%. For the monotonic output GDP growth, a minimum desirable value of $0 \%$ and an ideal value of $5 \%$ are considered. Similarly, for the monotonic output employment rate, a minimum desirable value of $70 \%$ and an ideal value of $100 \%$ are considered. The specific figures assumed for these membership functions are reasonable although subjective in some cases. Although the results can change when the reference values of these membership functions change, the results are not very sensitive in the sense that small changes in the membership functions lead to small changes in the results. Significantly different membership functions can, of course, lead to significantly different efficiency assessments.

Figure 6 (about here)

A consequence of the relatively narrow support of the desirability membership functions considered is the fact that not all the observed values of some of the variables are within their corresponding support. Take, for example, the GDP growth rate. The assumed desirability membership function considers negative values as completely undesirable. However, from 2008 to 2013 a number of countries have had negative GDP growth rates. One option would be to enlarge the support of that variable so as to include all the observed values, but that would mean considering negative real GDP growth rates as desirable. Instead of that, we have maintained the desirability membership functions indicated above and have modified the proposed non-monotonic DEA model to account for this case. This modified MILP model is presented in the Appendix.

Table 3 contains the efficiency score computed for each EU Member State in each year of the period 2006-2013 as per (19), assuming the desirability membership functions shown in Figure 6 and considering identical relative weights in the objective function. The rows shaded grey correspond to countries that have been efficient at least once in the period. 
It is not surprising that Luxembourg is the country with the highest average efficiency score in this period (0.956), due to its high GDP growth and employment rates, in addition to the taxation and public debts in the interval being assumed as ideal. On the other hand, Belgium and Greece have the worst average efficiency scores ( 0.541 and 0.526 , respectively). Note that, although Belgium had relatively high GDP growth and employment rates, its tax burden and debt levels are very far from those considered to be ideal. Because of such macroeconomic imbalances, the model estimates that such variables can be significantly improved and that is why it assesses Belgium as highly inefficient.

Table 3 (about here)

Since the proposed approach and corresponding results try to improve the macroeconomic variables as much as possible, the target computed may be very far from the observed DMU. Since, in this application, some of the variables have important political implications, it may be sensible to bound the allowed changes in those variables. Thus, we added the following two constraints establishing bounds on the relative change of the nonmonotonic variables.

$$
\begin{gathered}
\operatorname{tax}_{0} \cdot(1-\Delta) \leq \operatorname{tax} \leq \operatorname{tax}_{0} \cdot(1+\Delta) \\
\text { debt }_{0} \cdot(1-\Delta) \leq \widehat{\operatorname{debt}} \leq \operatorname{debt}_{0} \cdot(1+\Delta)
\end{gathered}
$$

Equations (20) and (21) indicate that the target values of the tax burden and the gross debt can only change by $\pm \Delta \%$ with respect to their current levels. We have not bounded the output variables because their direction of change is always for the better. In any case, since, according to the DEA production model shown in Figure 5, it is assumed that their levels result from those of the non-monotonic variables, the magnitude of their corresponding changes will also be bounded. Table 4 shows, for year 2013, the observed data and the targets computed by the proposed approach for two different bounds $(\boldsymbol{\Delta}=0.05$ and $\boldsymbol{\Delta}=0.10)$. The table also shows the targets computed without imposing (20) and (21), a case that, for simplicity, has been labeled $\Delta \rightarrow \infty$.

Note that, although for year 2013 only Germany and Luxembourg are efficient (their rows are shaded grey), the rest of the countries do not project onto them, but onto a linear combination of these two efficient countries. For example, when $\Delta \rightarrow \infty$, the EUMember 
States that have a negative GDP growth rate are projected onto (tax, debt, gdp, emp) $=(37.3$, $60.0,0.0,93.9)$. The rest of countries are projected onto $(\operatorname{tax}, \mathrm{debt}, \mathrm{gdp}, \mathrm{emp})=(40.0,24.5$, 4.4, 94.1), except Austria, which is projected onto a different target (tax, debt, gdp, emp) = (39.9, 61.9, 1.5, 94.6), among other things, because if it were projected onto any of the previous targets, its employment rate would have decreased (from $94.6 \%$ to $93.9 \%$ or $94.1 \%$, depending on the target), something which the model does not allow.

It can also be observed that the value of the outputs (GDP growth and employment rates) are generally lower for $\boldsymbol{\Delta}=0.05$ and $\boldsymbol{\Delta}=0.10$ for $\Delta \rightarrow \infty$, due to the bounds on the change of gross debt and tax burden, which tend to reduce the feasibility region of the optimization model. As expected, the inefficient EUMembers States that have a low level of taxes or debt, increase both variables in their targets, and for those that have a heavy tax burden or debt, the opposite happens. It is also no surprise that Austria has the same target level of employment (94.6) for every value of $\boldsymbol{\Delta}$. That is because there are no convex linear combinations of the observed DMUs with a higher value of this output. Note also that Ireland obtains the same targets when $\boldsymbol{\Delta}=0.05$ and $\boldsymbol{\Delta}=0.10$. However the targets considering $\Delta \rightarrow \infty$ change dramatically. We have checked out that for this country the targets begin to change again when $\boldsymbol{\Delta}=0.32$.

As regards The Netherlands, it presents an unusual evolution of the targets as $\boldsymbol{\Delta}$ increases. When the $\boldsymbol{\Delta}$ bounds on the changes of the target tax burden and debt are imposed, the targets computed have a lower tax burden than the observed value but when no bounds are imposed the target tax burden is higher. A similar effect occurs with the change in GDP growth rate. This is not what happens for most countries, for which the direction of change of the target variables for $\Delta=0.05, \Delta=0.10$ and $\Delta \rightarrow \infty$ is consistent. Take Belgium, for example. As $\Delta$ increases, the tax burden goes from the observed value of $47.8 \%$ to $45.4 \%$ to $43.0 \%$ to $40 \%(\Delta \rightarrow \infty)$ while the gross debt goes from $104.4 \%$ to $99.2 \%$ to $94 \%$ to $24.5 \%$ $(\Delta \rightarrow \infty)$ and the real GDP growth rate goes from $0.3 \%$ to $0.7 \%$ to $1 \%$ to $4.4 \%(\Delta \rightarrow \infty)$, and the employment rate goes from $91.6 \%$ to $91.9 \%$ to $92.2 \%$ to $94.0 \%$. In any case, the results with impose bounds on the relative changes of tax burden and gross debt are more realistic and implementable than those computed without impose those bounds, although the latter are more ambitious could be considered as long term targets. 


\section{Summary and conclusions}

This paper deals with those DEA applications in which certain variables cannot be labeled either as inputs or as outputs because their behavior depends on the values that they take. Thus, within a certain range, the variable can be considered as an output so that an increase in its value is desirable. However, within another range the opposite occurs, i.e. it behaves as an input whichit is desirable to decrease. We have labeled this type of variable non-monotonic to distinguish it from the conventional monotonic inputs and outputs.

The consideration of this type of variable forces a revision of the axioms used to derive the DEA technology. In particular, while the envelopment and convexity axioms do not pose any problems, the free disposability axiom cannot be applied to non-monotonic variables. This leads to a new technology that has been labeled non-monotonic DEA technology.

The definition of efficiency is maintained as a measure of the distance to the efficient frontier, which is formed by those feasible operation points for which no improvement is possible. Measuring improvements in conventional DEA is easy. It is just a matter of considering input reductions and output increases. All improvements have to be normalized (so that they become dimensionless) before aggregating them. In the case of non-monotonic variables it is not as easy since what is considered an improvement may be an increase or a decrease of the variable, depending on the range in which the variable lies. The solution proposed in this paper is to use a desirability membership function given by a TrFN. In this way, the improvements in the non-monotonic variable are measured by the increase in its corresponding membership function value. A desirability membership function has, therefore, to be specified for each non-monotonic variable and, in order to integrate these with the monotonic variables, the latter have also to be assigned appropriate desirability membership functions, ones that reflect their monotonic character.

The resulting non-monotonic DEA model is LP, provided that the observed values of all DMUs fall within the support of the corresponding variables (monotonic and nonmonotonic). If that is not the case, then those DMUs for which one or more variables fall outside the support of their corresponding membership function, a modified MILP model needs to be used, with two binary variables (or just one if it is a monotonic input or output) for each variable for which this happens. The modified model, included in the Appendix, is slightly more complex but not difficult to solve since the number of binary variables is rather small. 
The proposed approach has been applied to assess the macroeconomic efficiency of EU governments during the period 2006-2013. In this application, two non-monotonic variables have been assumed, namely tax burden and gross debt, both expressed as a \% of GDP. In addition, two (monotonic) outputs have been considered: real GDP growth rate and total employment rate. Since the 2006-2013 period contains a few pre-crisis years as well as other harder times which had a deeply disturbing effect on the public finances of many countries, the observed macroeconomic variables span a wide range of values for the different variables. The modified MILP model has been used often, since, for some variables, a number of observed values fall outside the support of their desirability membership function. The proposed approach computes efficiency scores for each country in each year as well as target values for each of the variables (monotonic and non-monotonic). Some countries (such as Luxembourg, Czech Republic, The Netherlands and Poland) have a high (above 0.900) average efficiency score in this period, which is no small feat. However, for most countries there are ups and downs in macroeconomic efficiency in this period of economic turbulence, not only in the EU but on a global scale.

Also, since in some cases the targets computed by the proposed approach were too ambitious and unreasonable in the short/medium term and as proof of the flexibility of the proposed approach, the model was solved including bounds on the relative changes allowed for the two non-monotonic variables. As expected, this leads to more realistic and implementable targets although, as a general rule, imposing bounds on the DEA projections does not guarantee that these lie on the efficient frontier.

Although the proposed approach is useful for handling non-monotonic variables that may appear in a DEA problem, like the application presented in this paper, it has its limitations. Thus, only a specific type of TrFN desirability membership function has been considered. In particular, it corresponds to variables that have an interval where they can be considered optimal and values below or above that interval are less desirable. But there can be variables whose non-monotonic character consists in that what is desirable is to stay away from a certain range of values. The approach proposed in this paper cannot handle those situations.

Note also that non-monotonic variables consider a situation different from the one addressed by dual role factors. In the latter case, the modeler does not know in advance whether a variable should be treated as an input or as an output and that is why the model reflects this uncertainty and has to identify the case. In the case of non-monotonic variables it 
is assumed that the modeler/DM knows ex-ante how the variable behaves depending on its value. Thus, within a range, it behaves as an input in the sense that lower values are preferred. In another range, the variable behaves as an output and larger values are preferred. There is also an intermediate range in which the change of the variable is neutral, and therefore it is considered neither as an input nor as an output. As one of the reviewers has suggested, a variant of the proposed approach might consider that in the intermediate range a nonmonotonic variable can work either as an input or as an output. It would be a sort of hybrid between the proposed approach and the DEA dual role factor approach. This is another interesting topic for further research.

\section{Appendix}

This section formulates and explains the modified model that must be used for those DMUs for which the observed value of at least one of the variables (monotonic or nonmonotonic) falls outside the support of the desirability membership function corresponding to that variable. Although the model below considers the worst case in which that happens for all variables, in most cases the corresponding modifications (which basically involve introducing one or two binary variables, depending on whether the variable with narrow support is a monotonic or a non-monotonic variable) need to be done only for the affected variables.

$$
\begin{aligned}
& \operatorname{Max} \sum_{\mathrm{r}=1}^{\mathrm{h}} \mathrm{w}_{\mathrm{r}}\left(\widehat{\mu}_{\mathrm{r}}^{\mathrm{non}_{\mathrm{m}}}-\mu_{\mathrm{r} 0}^{\mathrm{non}_{\mathrm{m}}}\right)+\sum_{\mathrm{i}=1}^{\mathrm{m}} \mathrm{w}_{\mathrm{i}}^{\prime}\left(\hat{\mu}_{\mathrm{i}}^{\mathrm{mi}}-\mu_{\mathrm{i} 0}^{\mathrm{mi}}\right)+\sum_{\mathrm{k}=1}^{\mathrm{p}} \mathrm{w}_{\mathrm{k}}^{\prime \prime}\left(\widehat{\mu}_{\mathrm{k}}^{\mathrm{mo}}-\mu_{\mathrm{k} 0}^{\mathrm{mo}}\right) \\
& \text { s.t. } \\
& \sum_{\mathrm{j}=1}^{\mathrm{n}} \lambda_{\mathrm{j}} \mathrm{x}_{\mathrm{ij}} \leq \mathrm{x}_{\mathrm{i} 0} \quad \forall \mathrm{i} \in \mathrm{I}^{\mathrm{mi}} \\
& \sum_{j=1}^{n} \lambda_{j} y_{k j} \geq y_{k 0} \quad \forall k \in 0^{m o} \\
& \sum_{j=1}^{n} \lambda_{j} x_{i j}=\hat{x}_{i} \quad \forall i \in I^{m i} \\
& \sum_{j=1}^{n} \lambda_{j} y_{k j}=\widehat{y}_{k} \quad \forall k \in 0^{m o} \\
& \sum_{j=1}^{n} \lambda_{j} v_{r j}=\widehat{v}_{r} \quad \forall r \in v^{\text {non }_{m}}
\end{aligned}
$$




$$
\begin{aligned}
& \hat{\mu}_{\mathrm{r}}^{\mathrm{non}_{\mathrm{m}}} \leq \frac{\widehat{\mathbf{v}}_{\mathrm{r}}-\mathbf{v}_{\mathrm{r}}^{\min }}{\mathbf{v}_{\mathrm{r}}^{\text {ideal,min }}-\mathbf{v}_{\mathrm{r}}^{\min \Xi}}+\mathrm{M} \delta_{\mathrm{r}}^{+} \quad \forall \mathrm{r} \in \mathbf{V}^{\mathrm{non}_{\mathrm{m}}} \\
& \frac{\widehat{\mathrm{v}}_{\mathbf{r}}-\mathrm{v}_{\mathrm{r}}^{\min }}{\mathrm{v}_{\mathrm{r}}^{\text {idealmin }}-\mathbf{v}_{\mathrm{r}}^{\min \amalg}} \leq \mathrm{M}\left(\mathbf{1}-\boldsymbol{\delta}_{\mathrm{r}}^{+}\right) \quad \forall \mathrm{r} \in \mathrm{V}^{\mathrm{non}_{\mathrm{m}}} \\
& \hat{\mu}_{\mathrm{r}}^{\mathrm{non}_{\mathrm{m}}} \leq \frac{\mathbf{v}_{\mathrm{r}}^{\max }-\widehat{v}_{\mathbf{r}}}{\mathbf{v}_{\mathbf{r}}^{\max }-\mathbf{v}_{\mathbf{r}}^{\text {ideal,max }}}+\mathbf{M} \delta_{\mathrm{r}}^{-} \quad \forall \mathrm{r} \in \mathbf{V}^{\mathrm{non}_{\mathrm{m}}} \\
& \frac{\mathbf{v}_{\mathbf{r}}^{\max }-\widehat{v}_{\mathbf{r}}}{\mathbf{v}_{\mathbf{r}}^{\max }-\mathbf{v}_{\mathbf{r}}^{\text {ideal,max }}} \leq \mathbf{M}\left(1-\delta_{\mathrm{r}}^{-}\right) \quad \forall \mathrm{r} \in \mathbf{V}^{\text {non }_{\mathrm{m}}} \\
& \tilde{\mu}_{\mathrm{i}}^{\mathrm{mi}} \leq \frac{\mathbf{x}_{\mathrm{i}}^{\max }-\hat{\mathbf{x}}_{\mathrm{i}}}{\mathbf{x}_{\mathrm{i}}^{\max }-\mathrm{x}_{\mathrm{i}}^{\min \Xi}}+\mathrm{M} \delta_{\mathrm{i}}^{-} \quad \quad \forall \mathrm{i} \quad \in \mathbf{I}^{\mathrm{mi}} \\
& \frac{\mathrm{x}_{\mathrm{i}}^{\max }-\hat{\mathrm{x}}_{\mathrm{i}}}{\mathrm{x}_{\mathrm{i}}^{\max }-\mathrm{x}_{\mathrm{i}}^{\min \Xi}} \leq \mathrm{M}\left(1-\delta_{\mathrm{i}}^{-}\right) \quad \quad \forall \mathrm{i} \quad \in \mathrm{I}^{\mathrm{mi}} \\
& \tilde{\mu}_{\mathrm{k}}^{\mathrm{mo}} \leq \frac{\widehat{\mathrm{y}}_{\mathrm{k}}-\mathrm{y}_{\mathrm{k}}^{\min }}{\mathrm{y}_{\mathrm{k}}^{\max }-\mathrm{y}_{\mathrm{k}}^{\min \Xi}}+\mathrm{M} \delta_{\mathrm{k}}^{+} \quad \forall \mathrm{k} \in \mathbf{0}^{\mathrm{mo}} \\
& \frac{\widehat{\mathrm{y}}_{\mathrm{k}}-\mathrm{y}_{\mathrm{k}}^{\min }}{\mathrm{y}_{\mathrm{k}}^{\max }-\mathrm{y}_{\mathrm{k}}^{\min \Xi}} \leq \mathrm{M}\left(1-\delta_{\mathrm{k}}^{+}\right) \quad \forall \mathrm{k} \in \mathrm{o}^{\mathrm{mo}} \\
& \sum_{j=1}^{n} \lambda_{j}=1 \\
& \mu_{\mathrm{r} 0}^{\mathrm{non}_{\mathrm{m}}} \leq \widehat{\mu}_{\mathrm{r}}^{\mathrm{non}_{\mathrm{m}}} \leq\left(1-\delta_{\mathrm{r}}^{+}-\delta_{\mathrm{r}}^{-}\right) \quad \forall \mathrm{r} \in \mathrm{V}^{\mathrm{non}_{\mathrm{m}}} \\
& \mu_{\mathrm{i} 0}^{\mathrm{mi}} \leq \widehat{\mu}_{\mathrm{i}}^{\mathrm{mi}} \leq\left(1-\delta_{\mathrm{i}}^{-}\right) \quad \forall \mathrm{i} \in \mathrm{I}^{\mathrm{mi}} \\
& \mu_{\mathrm{k} 0}^{\mathrm{mo}} \leq \widehat{\mu}_{\mathrm{k}}^{\mathrm{mo}} \leq\left(1-\delta_{\mathrm{k}}^{+}\right) \quad \forall \mathrm{k} \in \mathrm{o}^{\mathrm{mo}} \\
& \lambda_{\mathrm{j}} \geq \mathbf{0} \quad \forall \mathbf{j} \\
& \delta_{\mathrm{k}}^{+}, \delta_{\mathrm{i}}^{-}, \delta_{\mathrm{r}}^{+}, \delta_{\mathrm{r}}^{-}=\{0,1\} \quad \forall \mathrm{k} \in 0^{\mathrm{mo}} \quad \forall \mathrm{i} \in \mathrm{I}^{\mathrm{mi}} \forall \mathrm{r} \in \mathrm{V}^{\mathrm{non}_{\mathrm{m}}}
\end{aligned}
$$

Note that this is an MILP model with $2 * \mathrm{~h}+\mathrm{m}+\mathrm{p}$ binary variables included. $\mathrm{M}$ is a large enough positive number. Note that, for those variables not affected by the narrow support condition, the corresponding binary variables can be safely set to zero and the corresponding constraints will be equivalent to those in models (3)-(17).

The need for the modified formulation comes from the fact that the convex hull of the observed values contains operation points outside the support of some membership functions and therefore the target values can also be outside such support. Actually that is what we have referred to before as a narrow support condition. Let us analyze the modifications required by 
means of the following four cases. Any other case leads to assigning a zero value to the corresponding binary variables:

a) $\widehat{v}_{\mathbf{r}}<\mathbf{v}_{\mathbf{r}}^{\min \amalg}$

When $\widehat{v}_{\mathrm{r}}<\mathrm{v}_{\mathrm{r}}^{\min \square}$, we have

$\frac{\widehat{\mathbf{v}}_{\mathbf{r}}-\mathbf{v}_{\mathbf{r}}^{\min }}{\mathbf{v}_{\mathbf{r}}^{\text {ideal } \min }-\mathbf{v}_{\mathbf{r}}^{\min \mathbb{E}}}<0$

This forces the model to assign $\delta_{r}^{+}=1$ due to (A.7), $\mu_{\mathrm{r} 0}^{\mathrm{non}_{\mathrm{m}}} \geq 0$ (by definition of membership function) and (A.16). Note that (A.8) holds with either $\delta_{\mathbf{r}}^{+}=0$ or $\delta_{\mathrm{r}}^{+}=1$ in the case that $\widehat{\mathbf{v}}_{\mathbf{r}}<\mathbf{v}_{\mathbf{r}}^{\min \square}$.

On the other hand, as $\widehat{\mathbf{v}}_{\mathbf{r}}<\mathbf{v}_{\mathbf{r}}^{\min }<\mathbf{v}_{\mathbf{r}}^{\max }$,

$\frac{\mathbf{v}_{\mathbf{r}}^{\max }-\widehat{\mathbf{v}}_{\mathbf{r}}}{\mathbf{v}_{\mathbf{r}}^{\max }-\mathbf{v}_{\mathbf{r}}^{\text {ideal,max }}}>0$

forcing $\delta_{\mathbf{r}}^{-}=0$, due to (A.10). Note that (A.9) holds with either $\delta_{\mathbf{r}}^{-}=0$ or $\delta_{\mathbf{r}}^{-}=1$ in the case that $\widehat{v}_{\mathbf{r}}<v_{r}^{\min \square}$.

In the end, since $\delta_{r}^{+}=\mathbf{1}$ and $\delta_{\mathrm{r}}^{-}=\mathbf{0}$, we obtain that, because of constraint (A.16), $\hat{\mu}_{\mathrm{r}}^{\text {non }_{\mathrm{m}}}=0$.

b) $\widehat{v}_{\mathbf{r}}>\mathbf{v}_{\mathbf{r}}^{\max \Pi}$

In this case, we have

$\frac{\mathbf{v}_{\mathbf{r}}^{\max }-\widehat{v}_{\mathbf{r}}}{\mathbf{v}_{\mathbf{r}}^{\max }-\mathbf{v}_{\mathbf{r}}^{\text {ideal } \max }}<0$

forcing $\delta_{\mathrm{r}}^{-}=1$, due to (A.9), since $\mu_{\mathrm{ro}}^{\mathrm{non}_{\mathrm{m}}} \geq 0$.

As $\mathbf{v}_{\mathbf{r}}^{\min }<\mathbf{v}_{\mathbf{r}}^{\max }<\mathbf{v}_{\mathrm{r}}$

$\frac{\widehat{v}_{\mathbf{r}}-\mathbf{v}_{\mathbf{r}}^{\min }}{\mathbf{v}_{\mathbf{r}}^{\text {ideal,min }}-\mathbf{v}_{\mathrm{r}}^{\min }}>0$

making the model assign $\delta_{\mathrm{r}}^{+}=0$, due to (A.8).

In the end, since $\delta_{r}^{+}=\mathbf{0}$ and $\delta_{\mathrm{r}}^{-}=\mathbf{1}$, we obtain that, because of constraint (A.16), $\hat{\mu}_{\mathrm{r}}^{\text {non }_{\mathrm{m}}}=0$. 
c) $\hat{\mathbf{x}}_{\mathrm{i}}>\mathrm{x}_{\mathrm{i}}^{\max \amalg}$

In this case, we have

$\frac{\mathbf{x}_{\mathrm{i}}^{\max }-\hat{\mathbf{x}}_{\mathbf{i}}}{\mathbf{x}_{\mathrm{i}}^{\max }-\mathbf{x}_{\mathrm{i}}^{\min \Xi}}<0$

Hence, (A.11) determines that $\delta_{\mathrm{i}}^{-}=\mathbf{1}$ and, consequently, $\hat{\mu}_{\mathrm{i}}^{\mathrm{mi}}=\mathbf{0}$ due to the restriction (A.17). Note that (A.12) holds in this case with either $\delta_{\mathrm{i}}^{-}=\mathbf{1}$ or $\delta_{\mathrm{i}}^{-}=\mathbf{0}$.

d) $\widehat{y}_{\mathrm{k}}<\mathrm{y}_{\mathrm{k}}^{\min \mathrm{I}}$

In this case, we have

$$
\frac{\widehat{\mathrm{y}}_{\mathrm{k}}-\mathrm{y}_{\mathrm{k}}^{\min }}{\mathrm{y}_{\mathrm{k}}^{\max }-\mathrm{y}_{\mathrm{k}}^{\min \Xi}}<0
$$

Hence, (A.13) determines that $\delta_{\mathrm{k}}^{+}=\mathbf{1}$ and, therefore, $\hat{\mu}_{\mathrm{k}}^{\mathrm{mo}}=\mathbf{0}$ due to the restriction (A.18). Note that (A.14) holds in this case with either $\delta_{\mathrm{k}}^{+}=\mathbf{1}$ or $\delta_{\mathrm{k}}^{+}=0$.

\section{Acknowledgements}

This research was carried out with the financial support of the Spanish Ministry of Science grant DPI2013-41469-P and the European Regional Development Fund (ERDF). The authors are also grateful to the reviewers for their helpful comments and suggestions.

\section{References}

Afonso, A., Schuknecht, L. and Tanzi, V., "Public sector efficiency: An international comparison", Public Choice, 123, (2005) 321-347.

Amirteimoori, A. and Emrouznejad, A., "Flexible measures in production process: a DEAbased approach".RAIRO Operations Research, 45 (1),(2011) 63-74.

Amirteimoori, A. and Emrouznejad, A.,"Notes on 'Classifying inputs and outputs in data envelopment analysis' ”. Applied Mathematics Letters, 25, (2012) 1625-1628.

Amirteimoori, A., Emrouznejad, A.and Khoshandam, L.,"Classifying flexible measures in data envelopment analysis: A slack-based measure". Measurement, 46, (2013) 4100-4107.

Badun, M., Pribičević, V. and Deskar-Škrbić, M., "Government size and efficiency asconstraints to economic growth: comparing Croatia with other European countries", PostCommunist Economies, 26(3), (2014) 297-323.

Beasley, J., “Comparing university departments”. Omega 8 (2), (1990) 171-183. 
Beasley, J., "Determining teaching and research efficiencies".Journal of the Operational Research Society, 46, (1995) 441-452.

Chen, W., "Revisiting dual-role factors in data envelopment analysis: derivation and implications". IIE Transactions, 46, (2014) 653-663.

Claessens, S., "The Debt Laffer Curve: some estimates", World Development, 18 (12), (1990) 1671-1677.

Cook, W.D. and Zhu,J.,"Classifying inputs and outputs in DEA”. European Journal of Operational Research, 180, (2007) 692-699.

Cook, W.D.,Green, R.H. and Zhu,J.,"Dual-role factors in data envelopment analysis". IIE Transactions, 38, (2006) 105-115.

Cooper, W.W., Seiford, L.M. and Tone, K., Data Envelopment Analysis. A Comprehensive Text with Models, Applications, References and DEA-Solver Software.Kluwer Academic Publishers, 2000.

De Witte, K. and Moesen, W., "Sizing the government", Public Choice, 145 (2010) 39-55.

Eurostat Database (2015) http://ec.europa.eu/eurostat/data/database

Facchini, F. and Melki, M., "Efficient government size: France in the 20th century", European Journal of Political Economy, 31 (2013) 1-14.

Färe, R. and Grosskopf, S., New Directions: Efficiency and Productivity, Kluwer Academic Publishers, Boston, 2004.

Hauner, D. and Kyobe, A., "Determinants of Government Efficiency", World Development, 38, 11 (2010) 1527-1542.

Junker, J.C. “A New Start for Europe:My Agenda for Jobs,Growth, Fairness andDemocratic Change", Opening Statementin the European ParliamentPlenary Session2014.

Megersa, K. and Cassimon, D., "Public debt, economic growth, and public sector management in developing countries: is there a link?",Public Administration and Development, (2015) (doi: 10.1002/pad.1733)

Moreno, P. and Lozano, S., "Efficiency assessment of US states using Network DEA analysis", in Business Performance Measurement and Management, Charles, V. and Kumar, M. (Eds.), Cambridge Scholars Publishing (2014) 517-551.

Sahoo, B.K. and Acharya, D., "Constructing macroeconomic performance index of Indian states using DEA", Journal of Economic Studies, 39, 1 (2012) 63-83.

Shabani, A. and FarzipoorSaen, R., "The use of data envelopment analysis for international market selection in the presence of multiple dual-role factors". International Journal of Business Information Systems, 13 (4), (2013) 471-489.

Shabani, A. and FarzipoorSaen, R., "A new super-efficiency dual-role FDH procedure: An application in dairy cold chain for vehicle selection". International Journal of Shipping and Transport Logistics, 7 (4), (2015a) 426-456. 
Shabani, A. and FarzipoorSaen, R., "Developing a novel data envelopment analysis model to determine prospective benchmarks of green supply chain in the presence of dual-role factor".Benchmarking: An International Journal, 22 (4), (2015b) 711-730.

Shabani, A., Torabipour, S.M.R. and FarzipoorSaen, R., "Container selection in the presence of partial dual-role factors".International Journal of Physical Distribution \& Logistics Management, 41(10), (2011) 991-1008.

Toloo, M., "On classifying inputs and outputs in DEA: A revised model". European Journal of Operational Research, 198, (2009) 358-360.

Toloo, M., "Alternative solutions for classifying inputs and outputs in data envelopment analysis". Computers and Mathematics with Application, 63 (6), (2012) 1104-1110.

Toloo, M., "Notes on classifying inputs and outputs in data envelopment analysis: a comment". European Journal of Operational Research, 235 (3), (2014) 810-812.

Toloo, M. and Barat, M., "On considering dual-role factor in supplier selection problem". Mathematical Methods of Operations Research, 82, (2015) 107-122.

Tone, K., “A Slack-based measure of efficiency in DEA".European Journal of Operational Research, 130, (2001) 498-509.

Wang, E.C. and Alvi, E., "Relative Efficiency of Government Spending and Its Determinants: Evidence from East Asian Countries", Eurasian Economic Review, 1, 1 (2011) 3-28.

Zhu, J., Quantitative Models for Performance Evaluation and Benchmarking: Data Envelopment Analysis with Spreadsheets and DEA Excel Solver, Kluwer Academic Publishers, Boston, 2002. 


\section{List of figures and table captions}

Table 1. Observed values and results for the example shown in Figure 2.

Table 2. Summary statistics of tax revenues ( $\%$ of GDP), general government gross debt (\% of GDP), real GDP growth rate (\% change on previous year) and employment rate of EU countries (2006-2013).

Table 3. Efficiency scores $\xi_{0}$ of EU countries in the period 2006-2013.

Table 4. Observed and target values considering bounds on non-monotonic variables for year 2013.

Figure 1. Desirability membership functions for input, output and non-monotonic variables.

Figure 2. A single output/single non-monotonic variable example.

Figure 3. Other single output/single non-monotonic variable examples.

Figure 4. Real GDP growth rate and total employment rate versus tax revenue and gross debt (as \% of GDP)during period 2006 to 2013 (Source: Eurostat).

Figure 5. Macroeconomic efficiency of EU governments.

Figure 6. Desirability membership functions for macroeconomic efficiency variables considered. 


\begin{tabular}{|c|c|c|c|c|c|c|c|c|c|c|}
\hline & \multicolumn{4}{|c|}{ Data } & \multicolumn{6}{|c|}{ Results } \\
\hline DMU & $\mathbf{v}_{\mathbf{0}}$ & $\mathbf{y}_{\mathbf{0}}$ & $\mu_{0}^{\text {non }_{m}}$ & $\mu_{0}^{\mathrm{mo}}$ & $\xi_{0}$ & $\widehat{\mathbf{v}}_{0}$ & $\bar{y}_{0}$ & $\tilde{\mu}_{0}^{\text {non }_{m}}$ & $\tilde{\mu}_{0}^{\mathrm{mo}}$ & Benchmarks \\
\hline 1 & 54 & 8 & 0.65 & 0.12 & 0.463 & 43 & 28 & 0.93 & 0.92 & 3 \\
\hline 2 & 41 & 16 & 0.98 & 0.44 & 0.787 & 40 & 26.05 & 1.00 & 0.84 & 3,4 \\
\hline 3 & 43 & 28 & 0.93 & 0.92 & 1.000 & 43 & 28 & 0.93 & 0.92 & 3 \\
\hline 4 & 23 & 15 & 0.30 & 0.40 & 0.428 & 43 & 28 & 0.93 & 0.92 & 3 \\
\hline 5 & 74 & 15 & 0.15 & 0.40 & 0.353 & 43 & 28 & 0.93 & 0.92 & 3 \\
\hline 6 & 58 & 27 & 0.55 & 0.88 & 0.793 & 43 & 28 & 0.93 & 0.92 & 3 \\
\hline 7 & 48 & 20 & 0.80 & 0.60 & 0.778 & 43 & 28 & 0.93 & 0.92 & 3 \\
\hline 8 & 54 & 28 & 0.65 & 0.92 & 0.863 & 43 & 28 & 0.93 & 0.92 & 3 \\
\hline 9 & 30 & 12 & 1.00 & 0.28 & 0.719 & 40 & 26.05 & 1.00 & 0.84 & 3,4 \\
\hline 10 & 58 & 13 & 0.55 & 0.32 & 0.513 & 43 & 28 & 0.93 & 0.92 & 3 \\
\hline 11 & 70 & 11 & 0.25 & 0.24 & 0.323 & 43 & 28 & 0.93 & 0.92 & 3 \\
\hline
\end{tabular}

Table 1. Observed values and results for the example shown in Figure 2. 


\begin{tabular}{|c|c|c|c|c|c|c|c|c|c|}
\hline & Statistics & $\mathbf{2 0 0 6}$ & $\mathbf{2 0 0 7}$ & $\mathbf{2 0 0 8}$ & $\mathbf{2 0 0 9}$ & $\mathbf{2 0 1 0}$ & $\mathbf{2 0 1 1}$ & $\mathbf{2 0 1 2}$ & $\mathbf{2 0 1 3}$ \\
\hline \multirow{4}{*}{ tax } & Min & 28.4 & 28.9 & 26.1 & 27.2 & 27 & 26.1 & 27.2 & 27.2 \\
\cline { 2 - 10 } & Max & 47.7 & 47.8 & 46.6 & 46.5 & 46.6 & 46.6 & 47.5 & 48.6 \\
\cline { 2 - 10 } & Average & 36.96 & 36.57 & 35.75 & 35.92 & 35.66 & 35.75 & 36.25 & 36.76 \\
\hline \multirow{4}{*}{ debt } & Min & 4.4 & 4.4 & 4.5 & 7 & 6.5 & 6 & 9.7 & 10.1 \\
\cline { 2 - 10 } & Max & 102.5 & 101.9 & 102.3 & 112.5 & 115.3 & 171.3 & 156.9 & 175 \\
\cline { 2 - 10 } gdp & Average & 42.75 & 43.91 & 43.77 & 52.37 & 57.52 & 65.02 & 68.59 & 72.18 \\
\cline { 2 - 10 } & Min & 1.6 & 0.5 & -5.4 & -14.8 & -2.9 & -8.9 & -6.6 & -5.4 \\
\cline { 2 - 10 } & Max & 11.6 & 11.1 & 8.5 & 2.6 & 6 & 7.6 & 5.2 & 4.4 \\
\hline \multirow{3}{*}{ emp } & Merage & 5.03 & 5.05 & 1.30 & -5.74 & 1.87 & 1.80 & -0.24 & 0.41 \\
\cline { 2 - 10 } & Max & 86.1 & 88.8 & 88.7 & 82.1 & 80.1 & 78.6 & 75.2 & 72.5 \\
\cline { 2 - 9 } & Average & 92.56 & 93.54 & 93.66 & 91.10 & 89.94 & 89.90 & 89.18 & 88.85 \\
\hline
\end{tabular}

Table 2. Summary statistics of tax revenues ( $\%$ of GDP), general government gross debt (\% of GDP), real GDP growth rate (\% change on previous year) and employment rate of EU countries (2006-2013). 


\section{Year}

\begin{tabular}{|c|c|c|c|c|c|c|c|c|c|c|}
\hline Country & $\begin{array}{c}\text { Country } \\
\text { code }\end{array}$ & 2006 & 2007 & 2008 & 2009 & 2010 & 2011 & 2012 & 2013 & Aver. \\
\hline Belgium & $\mathrm{BE}$ & 0.591 & .610 & 0.493 & 0.691 & 0.547 & 0.529 & 0.473 & .396 & .541 \\
\hline Bulgaria & $\mathrm{G}$ & .964 & 976 & 0.796 & 885 & 588 & 627 & 614 & 683 & .767 \\
\hline & & 0.981 & .989 & 0.884 & 0.981 & 0.843 & 0.891 & 0.984 & 0.993 & 0.943 \\
\hline Denmark & & 1.000 & 1.000 & 1.000 & 0.824 & 0.641 & .656 & 0.792 & 0.778 & .836 \\
\hline Germa & & 0.860 & 0.850 & 0.757 & 0.921 & 0.850 & 1.000 & 0.894 & .000 & .892 \\
\hline Estonia & $\mathrm{EE}$ & 1.000 & 0.856 & 0.850 & 0.849 & 0.687 & 1.000 & 1.000 & 0.840 & 0.885 \\
\hline Ireland & IE & 1.000 & 0.988 & 0.920 & 0.892 & 0.508 & 0.561 & 0.645 & 0.482 & 0.750 \\
\hline Greece & & - & - & - & - & - & 0.417 & 0.588 & 0.572 & 0.526 \\
\hline Spain & & 0.925 & 904 & 0.746 & 0.888 & 0.622 & 0.600 & 0.734 & 0.700 & 0.765 \\
\hline France & & 0.707 & 0.836 & 0.570 & 0.788 & 0.618 & 0.610 & 0.476 & 0.464 & 0.634 \\
\hline Croatia & & 0.929 & 0.798 & 0.819 & 0.960 & 0.691 & 0.687 & 0.871 & 0.821 & 0.822 \\
\hline Italy & IT & 0.612 & .807 & 0.759 & 0.704 & 0.530 & 0.499 & 0.621 & 0.615 & 0.643 \\
\hline Cyprus & $\mathrm{CY}$ & 0.973 & 0.832 & 1.000 & 1.000 & 0.806 & 0.742 & 0.862 & 0.743 & 0.870 \\
\hline Latvia & $\mathrm{LV}$ & 1.000 & 0.970 & 0.864 & 0.761 & 0.506 & 0.826 & 0.861 & 0.847 & 0.829 \\
\hline Lithuania & LT & 0.993 & 0.945 & 0.737 & 0.922 & 0.645 & 0.823 & 0.769 & 0.758 & 0.824 \\
\hline Luxembourg & $\mathrm{LU}$ & 0.923 & 0.999 & 0.745 & 0.989 & 1.000 & 0901 & 1.000 & 1.000 & 0.956 \\
\hline Hungary & $\mathrm{HU}$ & 0.903 & 0.653 & 0.716 & 0.878 & 0.648 & 0797 & 0.873 & 0.749 & 0.768 \\
\hline Malta & & 0.800 & & 0.889 & 0.953 & 0.874 & .000 & 1.000 & 0.870 & 0.897 \\
\hline & & & & 0.905 & 100 & 0.817 & 0.950 & 0.967 & 0.954 & 0.923 \\
\hline Austria & AI & 0.845 & 0.922 & 0.761 & 0.860 & 0.705 & 1.000 & 1.000 & 0.777 & 0.859 \\
\hline Poland & PL & 0.923 & 882 & 0.921 & 1.000 & 0.893 & 0.976 & 0.837 & 0.831 & 0.908 \\
\hline Portugal & PT & 53 & 332 & 0.673 & .853 & 0.633 & 0.496 & 0.661 & 0.664 & 0.696 \\
\hline Romania & RO & 0.964 & 0.949 & 1.000 & 0.843 & 0.585 & 0.734 & 0.792 & 0.812 & 0.835 \\
\hline Slovenia & SI & 0.988 & 0.943 & 0.914 & 0.988 & 0.788 & 0.778 & 0.968 & 0.924 & 0.911 \\
\hline Slovakia & SK & 0.892 & 0.942 & 0.897 & 0.881 & 0.818 & 0.777 & 0.714 & 0.783 & 0.838 \\
\hline & FI & 0.887 & 0.940 & 0.712 & 0.941 & 0.846 & 0.830 & 0.908 & 0.883 & 0.868 \\
\hline Sweden & SE & 0.817 & 0.844 & 0.626 & 0.840 & 1.000 & 0.783 & 0.866 & 0.712 & 0.811 \\
\hline $\begin{array}{c}\text { United } \\
\text { Kingdom }\end{array}$ & UK & 0.891 & 0.698 & 0.739 & 0.949 & 0.750 & 0.738 & 0.744 & 0.739 & 0.781 \\
\hline
\end{tabular}

Table 3. Efficiency scores $\xi_{0}$ of EU countries in the period 2006-2013. 


\begin{tabular}{|c|c|c|c|c|c|c|c|c|c|c|c|c|c|c|c|c|}
\hline \multirow[b]{2}{*}{ Country } & \multicolumn{4}{|c|}{ Tax revenue (\% of GDP) } & \multicolumn{4}{|c|}{ Gross debt (\% of GDP) } & \multicolumn{4}{|c|}{ Real GDP growth rate $(\%)$} & \multicolumn{4}{|c|}{ Total employment rate (\%) } \\
\hline & Observ. & $\Delta=\mathbf{0 . 0 5}$ & $\Delta=\mathbf{0 . 1}$ & $\Delta \rightarrow \infty$ & Observ. & $\Delta=\mathbf{0 . 0 5}$ & $\Delta=\mathbf{0 . 1}$ & $\Delta \rightarrow \infty$ & Observ. & $\Delta=\mathbf{0 . 0 5}$ & $\Delta=\mathbf{0 . 1}$ & $\Delta \rightarrow \infty$ & Observ. & $\Delta=\mathbf{0 . 0 5}$ & $\Delta=\mathbf{0 . 1}$ & $\Delta \rightarrow \infty$ \\
\hline $\mathrm{BE}$ & 47.8 & 45.4 & 43.0 & 40.0 & 104.4 & 99.2 & 94.0 & 24.5 & 0.3 & 0.7 & 1.0 & 4.4 & 91.6 & 91.9 & 92.2 & 94.1 \\
\hline $\mathrm{BG}$ & 28.1 & 29.5 & 30.9 & 40.0 & 18.3 & 19.2 & 20.1 & 24.5 & 1.1 & 1.8 & 2.4 & 4.4 & 87.0 & 90.0 & 92.0 & 94.1 \\
\hline $\mathrm{CZ}$ & 34.9 & 36.7 & 38.1 & 37.3 & 45.0 & 42.8 & 40.5 & 60.0 & -0.5 & 3.6 & 3.7 & 0.0 & 93.0 & 93.8 & 93.9 & 93.9 \\
\hline DK & 48.6 & 46.2 & 43.7 & 37.3 & 45.0 & 47.3 & 49.5 & 60.0 & -0.5 & 1.0 & 2.5 & 0.0 & 93.0 & 93.1 & 93.2 & 93.9 \\
\hline $\mathrm{DE}$ & 39.6 & 39.6 & 39.6 & 39.6 & 77.1 & 77.1 & 77.1 & 77.1 & 0.3 & 0.3 & 0.3 & 0.3 & 94.8 & 94.8 & 94.8 & 94.8 \\
\hline $\mathrm{EE}$ & 32.0 & 32.3 & 32.6 & 40.0 & 10.1 & 10.6 & 11.1 & 24.5 & 1.6 & 1.7 & 1.8 & 4.4 & 91.4 & 91.5 & 91.6 & 94.1 \\
\hline $\mathrm{IE}$ & 30.3 & 30.8 & 30.8 & 40.0 & 123.2 & 120.0 & 120.0 & 24.5 & 0.2 & 0.3 & 0.3 & 4.4 & 86.9 & 87.4 & 87.4 & 94.1 \\
\hline EL & 37.1 & 38.3 & 39.5 & 40.0 & 175.0 & 166.3 & 157.5 & 60.0 & -3.9 & -3.5 & -3.1 & 0.0 & 72.5 & 75.4 & 78.3 & 93.9 \\
\hline ES & 33.2 & 34.9 & 36.5 & 37.3 & 92.1 & 87.5 & 82.9 & 60.0 & -1.2 & -1.0 & -1.0 & 0.0 & 73.9 & 90.5 & 91.7 & 93.9 \\
\hline FR & 47.3 & 44.9 & 42.6 & 40.0 & 92.3 & 87.7 & 83.1 & 24.5 & 0.7 & 1.2 & 1.5 & 4.4 & 89.7 & 92.2 & 92.5 & 94.1 \\
\hline HR & 36.5 & 34.7 & 34.2 & 40.0 & 80.6 & 76.6 & 72.5 & 60.0 & -0.9 & 2.2 & 2.4 & 0.0 & 82.7 & 93.1 & 93.4 & 93.9 \\
\hline IT & 43.4 & 41.2 & 40.0 & 37.3 & 128.5 & 122.1 & 120.0 & 60.0 & -1.7 & -1.2 & -1.0 & 0.0 & 87.9 & 88.5 & 88.7 & 93.9 \\
\hline $\mathrm{CY}$ & 31.6 & 33.2 & 34.8 & 37.3 & 102.2 & 97.1 & 92.0 & 60.0 & -5.4 & -1.0 & -1.0 & 0.0 & 84.1 & 89.0 & 90.2 & 93.9 \\
\hline LV & 28.1 & 29.5 & 30.9 & 40.0 & 38.2 & 36.6 & 34.9 & 24.5 & 4.2 & 4.2 & 4.2 & 4.4 & 88.1 & 88.9 & 89.8 & 94.1 \\
\hline LT & 27.2 & 28.6 & 29.9 & 40.0 & 38.8 & 36.9 & 35.3 & 24.5 & 3.3 & 3.5 & 3.6 & 4.4 & 88.2 & 93.0 & 93.1 & 94.1 \\
\hline $\mathrm{LU}$ & 40.5 & 40.5 & 40.5 & 40.5 & 24.0 & 24.0 & 24.0 & 24.0 & 4.4 & 4.4 & 4.4 & 4.4 & 94.1 & 94.1 & 94.1 & 94.1 \\
\hline $\mathrm{HU}$ & 38.5 & 36.6 & 34.7 & 40.0 & 77.3 & 73.4 & 69.6 & 24.5 & 1.5 & 2.3 & 2.6 & 4.4 & 89.8 & 93.3 & 93.5 & 94.1 \\
\hline MT & 34.0 & 34.5 & 35.0 & 40.0 & 69.2 & 65.7 & 62.3 & 24.5 & 2.6 & 2.7 & 2.9 & 4.4 & 93.6 & 93.6 & 93.7 & 94.1 \\
\hline $\mathrm{NL}$ & 37.7 & 35.8 & 35.1 & 40.0 & 68.6 & 65.2 & 61.7 & 60.0 & -0.5 & 2.7 & 2.9 & 0.0 & 92.7 & 93.5 & 93.7 & 93.9 \\
\hline AT & 43.4 & 41.2 & 39.1 & 39.9 & 80.9 & 76.9 & 72.8 & 61.9 & 0.3 & 0.6 & 0.9 & 1.5 & 94.6 & 94.6 & 94.6 & 94.6 \\
\hline $\mathrm{PL}$ & 32.7 & 34.3 & 36.0 & 40.0 & 55.7 & 52.9 & 50.1 & 24.5 & 1.7 & 3.2 & 3.3 & 4.4 & 89.7 & 93.6 & 93.7 & 94.1 \\
\hline $\mathrm{PT}$ & 37.6 & 39.5 & 40.0 & 40.0 & 129.7 & 123.2 & 120.0 & 60.0 & -1.6 & -1.0 & -1.0 & 0.0 & 83.6 & 88.1 & 88.7 & 93.9 \\
\hline $\mathrm{RO}$ & 27.4 & 28.8 & 30.1 & 40.0 & 38.0 & 36.5 & 35.1 & 24.5 & 3.4 & 3.5 & 3.6 & 4.4 & 92.9 & 93.0 & 93.2 & 94.1 \\
\hline SI & 37.3 & 36.2 & 35.8 & 40.0 & 70.3 & 66.8 & 63.3 & 60.0 & -1.1 & -1.0 & -1.0 & 0.0 & 89.9 & 92.2 & 92.2 & 93.9 \\
\hline SK & 30.4 & 31.9 & 33.4 & 40.0 & 54.6 & 51.9 & 49.1 & 24.5 & 1.4 & 3.1 & 3.3 & 4.4 & 85.8 & 93.4 & 93.5 & 94.1 \\
\hline FI & 44.0 & 41.8 & 39.6 & 37.3 & 55.8 & 58.6 & 60.0 & 60.0 & -1.1 & -1.0 & -1.0 & 0.0 & 91.8 & 92.2 & 92.2 & 93.9 \\
\hline $\mathrm{SE}$ & 44.7 & 42.5 & 40.2 & 40.0 & 38.7 & 40.6 & 34.8 & 24.5 & 1.3 & 3.3 & 3.9 & 4.4 & 92.0 & 93.6 & 93.9 & 94.1 \\
\hline UK & 35.3 & 35.0 & 34.7 & 40.0 & 87.3 & 82.9 & 78.6 & 24.5 & 1.7 & 1.9 & 2.1 & 4.4 & 92.4 & 92.7 & 93.0 & 94.1 \\
\hline
\end{tabular}

Table 4. Observed and target values considering bounds on non-monotonic variables for year 2013. 

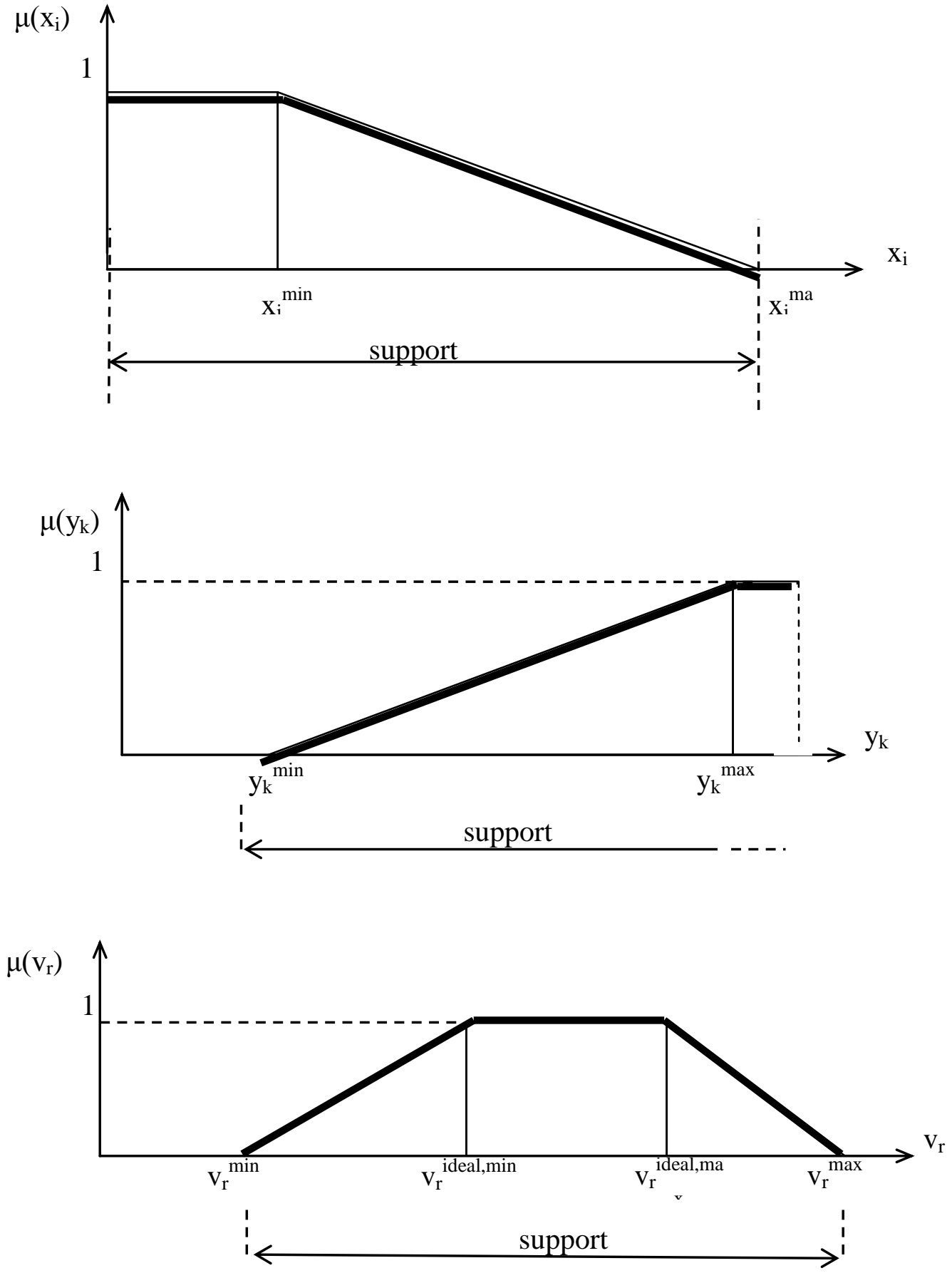

Figure 1. Desirability membership functions for input, output and non-monotonic variables. 


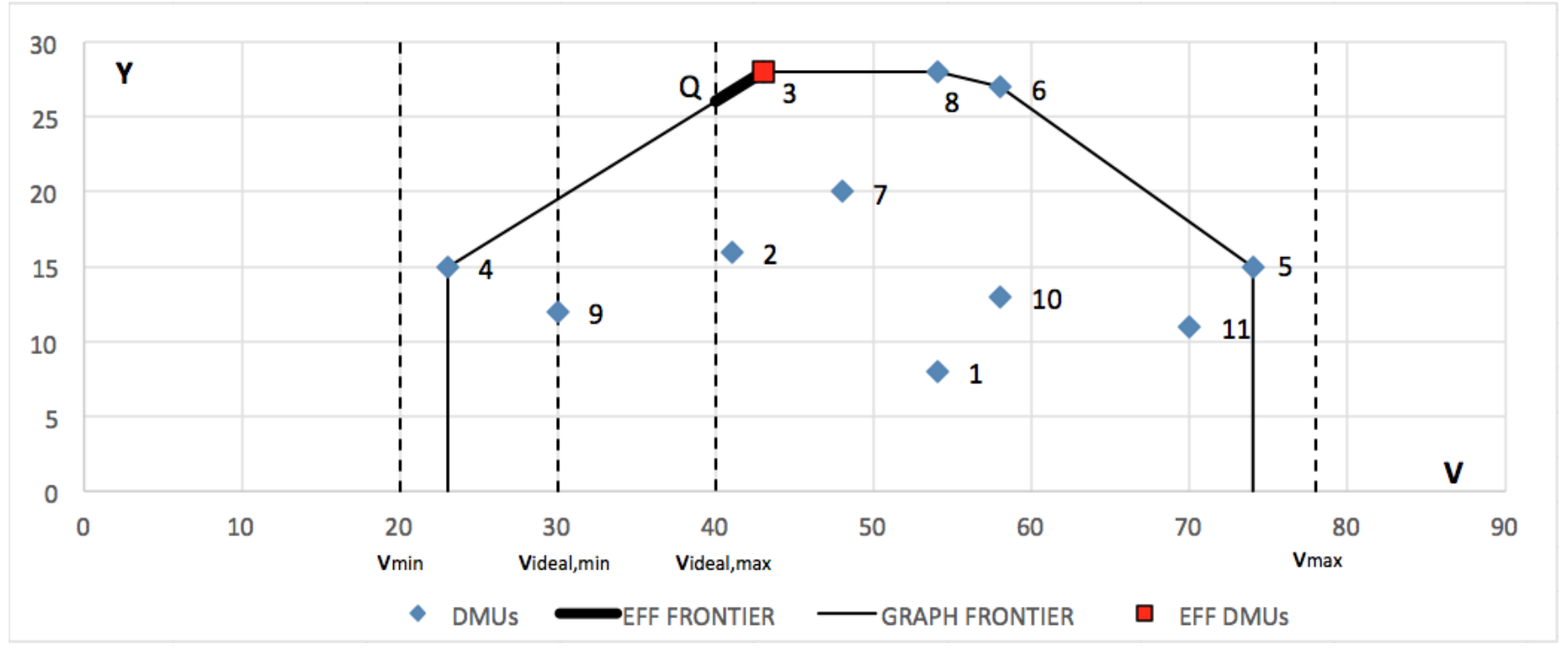

Figure 2. A single output/single non-monotonic variable example. 
a)

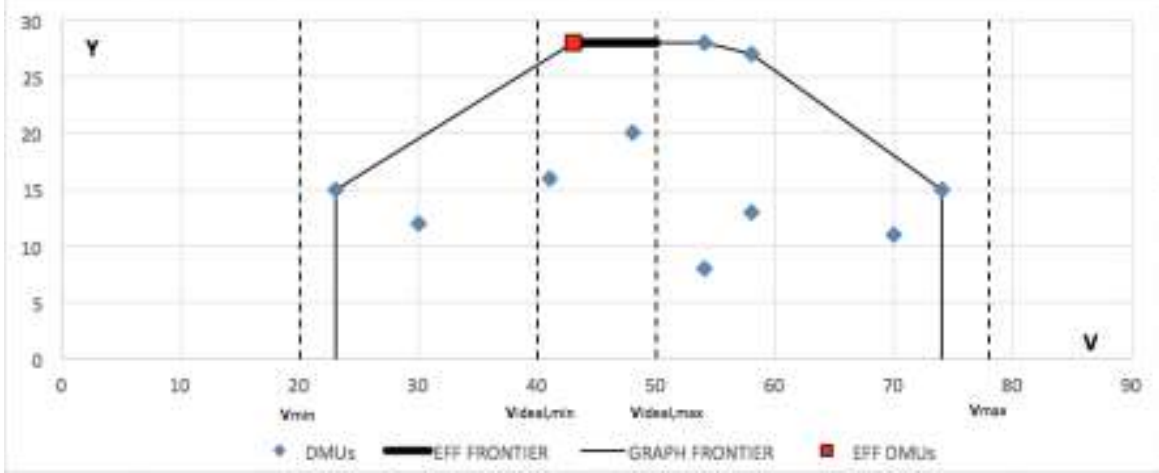

c)

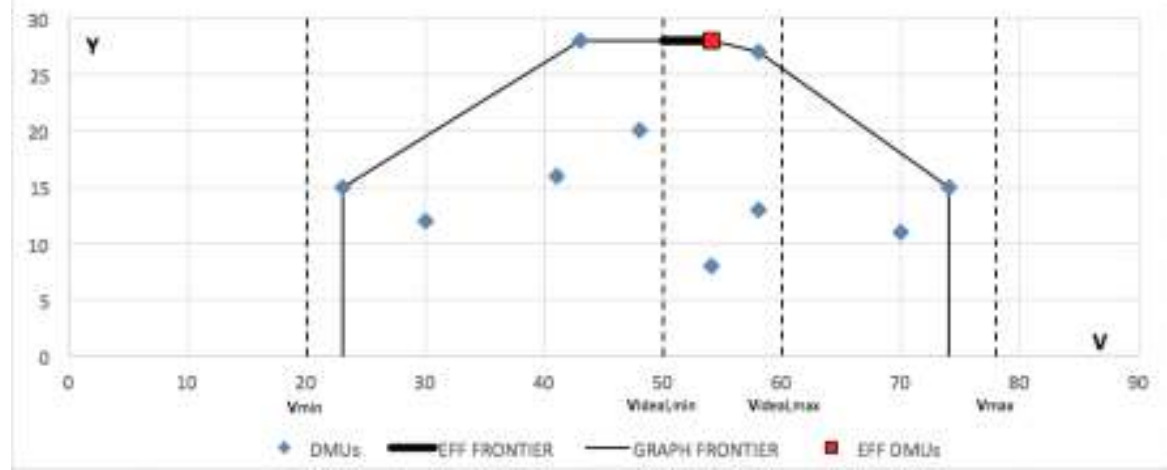

b)

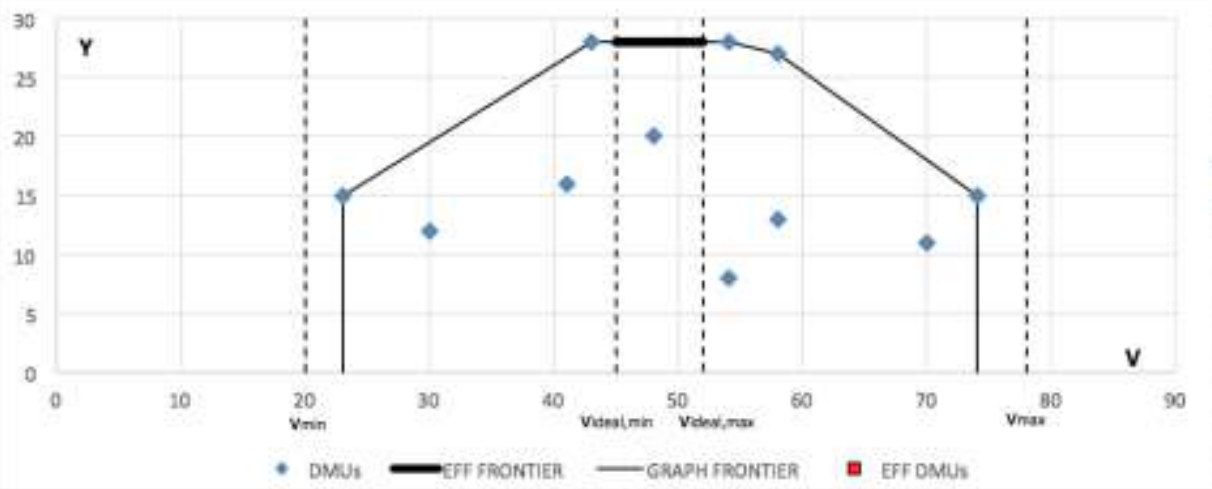

d)

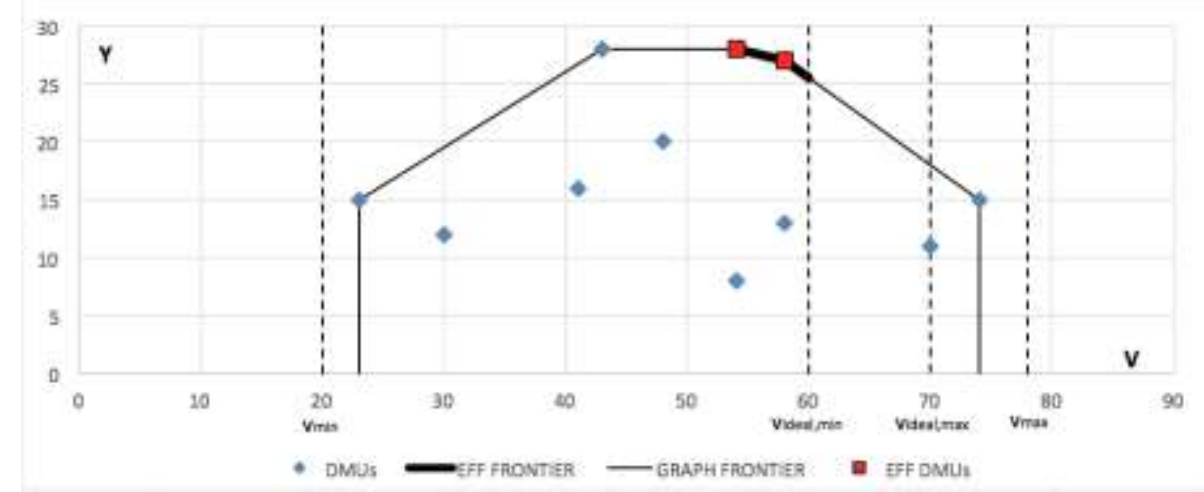

Figure 3. Other single output/single non-monotonic variable examples. 

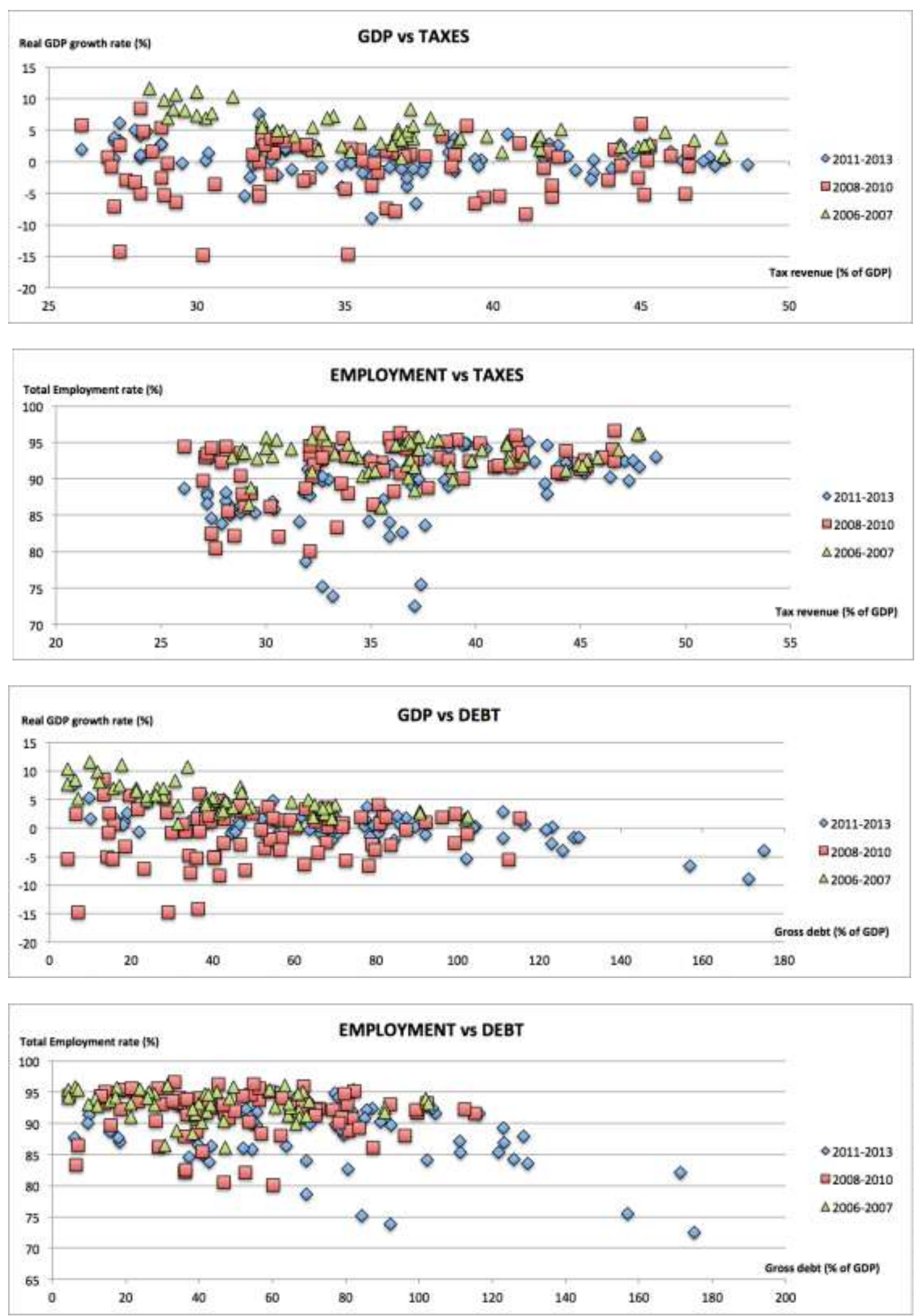

Figure 4. Real GDP growth rate and total employment rate versus tax revenue and gross debt (as \% of GDP) during period 2006 to 2013 (Source: Eurostat). 


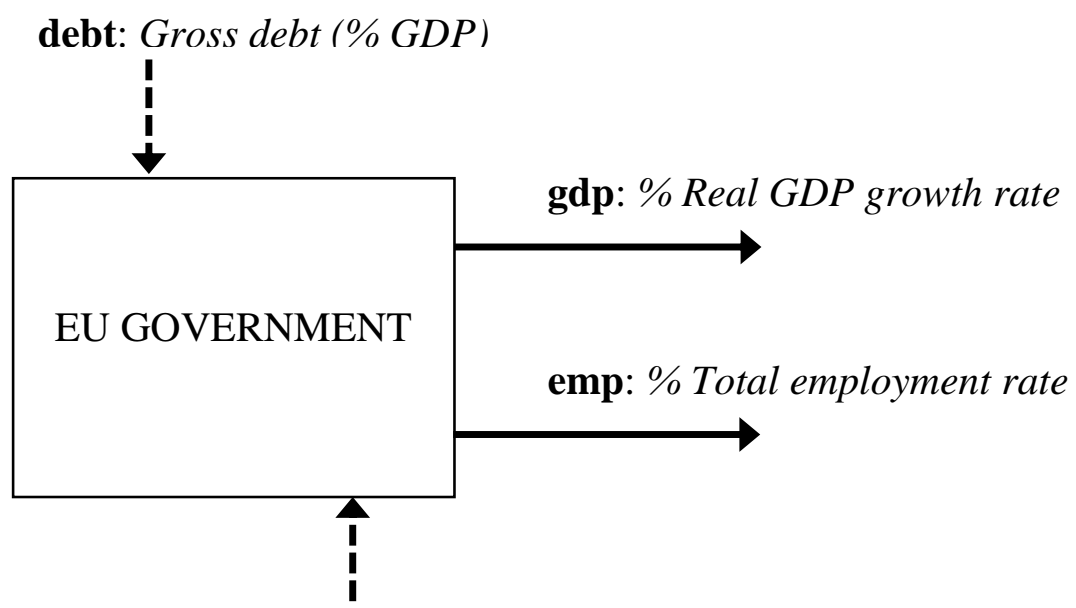

tax: Tax revenues (\% of GDP)

Figure 5. Macroeconomic efficiency of EU governments. 

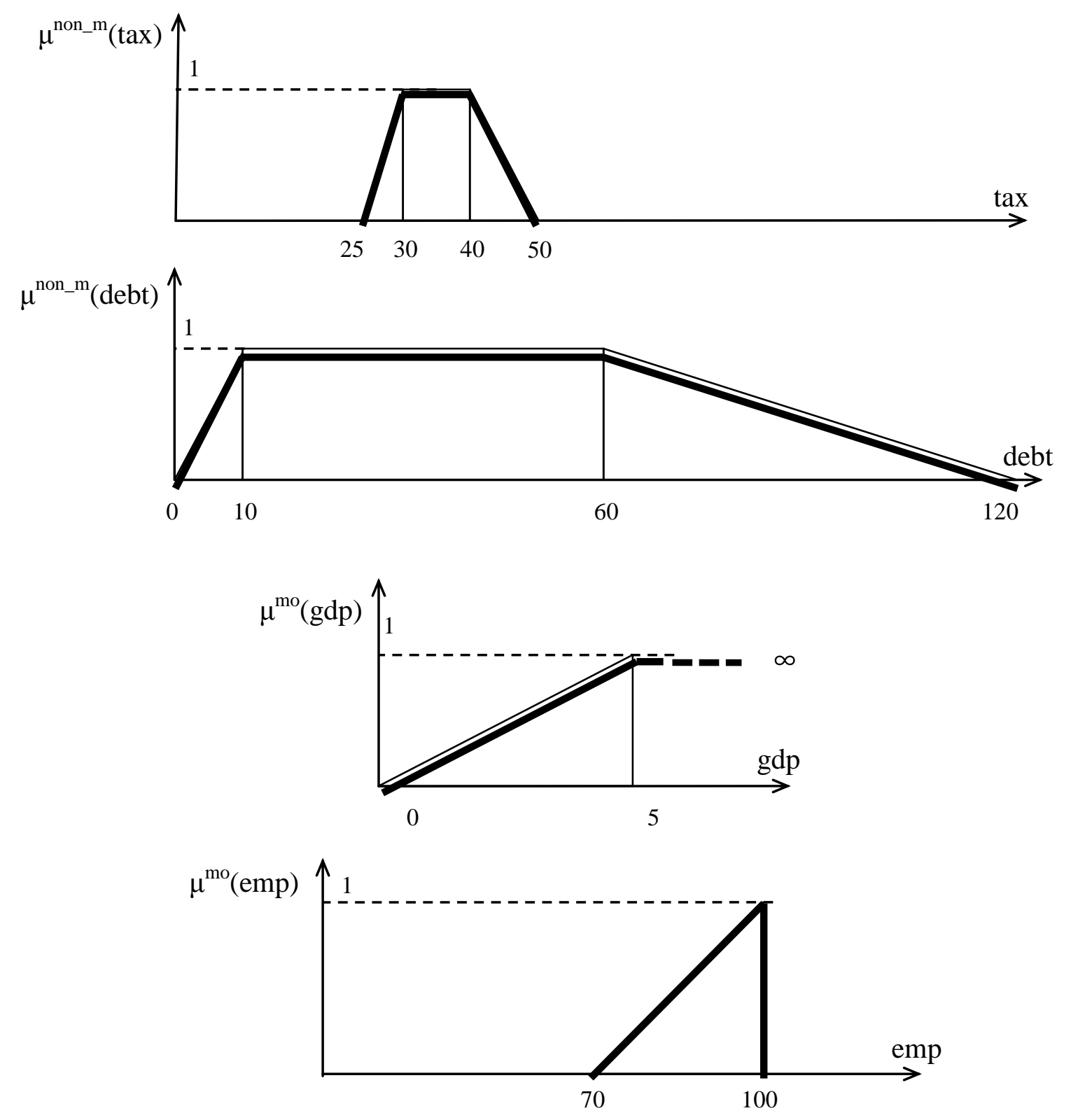

Figure 6.Desirability membership functions for macroeconomic efficiency variables considered. 